\title{
Portland Cement-Residues-Polymers Composites and Its Application to the Hollow Blocks Manufacturing
}

\author{
Augusto Cesare Stancato ${ }^{1}$, Antonio Ludovico Beraldo ${ }^{2 *}$ \\ ${ }^{1}$ State University of Campinas, Program in Agricultural Engineering (FEAGRI), Cidade Universitária Zeferino Vaz, Campinas, \\ Brasil; ${ }^{2}$ State University of Campinas-FEAGRI, Cidade Universitária Zeferino Vaz, Campinas, Brasil. \\ Email: *augustostancato@saae.sp.gov.br
}

Received August $20^{\text {th }}, 2012$; revised September $25^{\text {th }}, 2012$; accepted October $8^{\text {th }}, 2012$

\begin{abstract}
Agricultural wastes and sawdust combined with cement matrix in the manufacture of building elements has been practiced with success in developed countries. In this study, sawdust from wood species (Pinus caribaea and Eucalyptus grandis) and an agricultural waste - rice husk (Oriza sativa) were combined with Portland cement type V (high initial strength), modified by polymer styrene-butadiene (SBR) addition. Hollow blocks produced with Eucalyptus grandis and rice husk residues showed better compressive strength; however, those produced with residues derived from Pinus caribaea presented non-satisfactory results, due to the particle size that was used.
\end{abstract}

Keywords: Composites Cement; Residues; Hollow Blocks; Ultrasonic Pulse Velocity (UPV)

\section{Introduction}

The transformation of sawdust and residues into inert raw material to be used in the manufacture of building components, such as prefabricated hollow blocks and wavy tiles, among others, demands planning and study aiming to produce a non conventional material. Evaluating how to use the residues, in an efficient way, in the blend with the Portland cement and to judiciously analyze the behavior of the so obtained composite becomes a challenge. At the moment of the blend of the components, known as the fresh state, the situation is the most critical because in this period the hydration process of the cement happens and, consequently, the formation of products derived from its reaction, which will grant physical stability to the structure of the new material obtained. The addition of these materials in the water-cement blend increases the hydration time of the binder and influences the mechanical resistance of the cement paste. The water soluble compounds present in the residues retard the setting and inhibit the hardening of the blend [1]. The mechanism of cement hydration and crystallization inhibition, provoked by the components of the biomass, is just superficially known. These inhibitor reactions may be developed in the interface between the biomass and the cement or in the vicinities of the cement matrix, reducing the mechanical and chemical links that exist there [2]. The employment of agricultural residues in the hollow blocks manufacturing is based upon cement addi-

*Corresponding author. tives has contribution at the reutilization of raw material in a rational and ecologically correct way, without causing damage to the environment. So, it is necessary to develop appropriate methodologies to evaluate these materials, aiming that the final product is in conformity with the specific standards for the hollow blocks (Brazilian Association of Technical Standard-ABNT), regarding to the compressive strength and water absorption limits. The main objective of this research work was to evaluate the feasibility of biomass waste application for hollow blocks manufacturing.

\section{Material and Methods}

Biomass waste was supplied by industries at Campinas region. Mineral aggregate was formed of fine washed sand and the stone powder came from a stone quarry. Portland cement type V, high initial strength cement [3], was employed as a binder (Table 1).

The polymer was supplied by Rhodia of Brazil, and was constituted by the water dispersion of copolymer styrene-butadiene (SBR). The technical information is described in Table 2. The addition of the polymer SBR to the blends based on cement, granted a decrease of porosity, permeability and water absorption, constituting one of the most significant characteristics observed in these composites [4].

\subsection{Residues Treatment}

The goal of the treatments was to reduce the inhibition 
Table 1. Physical characteristics of the cement (CPV-ARI).

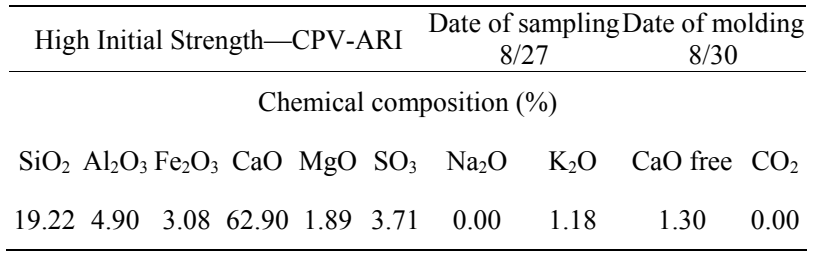

Source: Lafarge of Brazil—cement CPV-ARI "Campeão".

Table 2. Properties of polymer SBR (styrene and butadiene).

\begin{tabular}{cccccc}
\hline \multicolumn{5}{c}{ Properties of SBR (styrene-butadiene) } \\
\hline $\begin{array}{c}\text { Polymer } \\
\text { type }\end{array}$ & $\begin{array}{c}\text { Particle } \\
\text { diameter } \\
(\mu \mathrm{m})\end{array}$ & $\begin{array}{c}\text { (fuso 2.50 rpm, } \\
\left.23^{\circ} \mathrm{C}\right)\end{array}$ & $\mathrm{pH}$ & $\begin{array}{c}\text { Solid } \\
\text { contents } \\
(\%)\end{array}$ & $\begin{array}{c}\text { Density } \\
\left(\mathrm{g} \cdot \mathrm{cm}^{-3}\right)\end{array}$ \\
SBR & 160 & $75-125$ & $7.0-8.0$ & $49 \%-51 \%$ & 1.02 \\
\hline
\end{tabular}

Source: Rhodia of Brazil. Note: The temperature of decomposition of SBR is $320^{\circ} \mathrm{C}$ (after water evaporation).

between the cement and the biomass residues, and thereby decreasing the influence of the water soluble compounds present in the residues during the periods of setting and hardening of the blends. The treatment of the residues derived from $P$. caribaea and E. grandis were performed through the immersion of the residues in lime solution, during a period of $24 \mathrm{~h}$, in the proportion of $5 \%$ related to the mass of residue and taking into account the results of compressive strength of the composites, that was about 8.0 $\mathrm{MPa}$ [5] for the blend of 1:0.375:0.75 (cement:residue:water) and setting accelerators $\mathrm{CaCl}_{2}$ and $\mathrm{Al}_{2}\left(\mathrm{SO}_{4}\right)_{3}$. The rice husk treatment was also performed through the immersion in lime solution corresponding to the best performance, when related to the mechanical results in the blend of 1:0.36:0.50 (cement:husk rice: water). After reviewing these results, the follow blends were proposed, as described in Table 3.

\subsection{Procedure of Blending, Molding and Hardening of the Hollow Blocks}

Hollow blocks were produced in laboratory, using a manual molding equipment, model Permaq MBM 050, vibro pressing machine. At the first stage, constant polymer content was used for all the blends, which corresponded to $5 \%$ in mass [4], to evaluate the behavior of the heat hydration. It is worthy of pointing out that for the hollow blocks, the polymer content (SBR) used was based on the best mechanical performance previously obtained in the compressive test of cylindrical specimens ( $5 \mathrm{~cm}$ in diameter and $10 \mathrm{~cm}$ in height). In this way, the blends for the new compositions were produced in a concrete mixer, with the addition of the dry materials and, afterwards, of polymer (SBR), related to each type of residue, diluted in water. The composition used in the hollow blocks manufacturing was based mainly upon the best results of the heat hydration tests (Table 4) according [6].

After molding, the hollow blocks were storage in a wet chamber for 7 days. With the results obtained from the compressive test, hollow blocks were produced according to the industrial manufacturing process. Then the blend was produced in a concrete mixer and thrown directly into the molds of the industry device. From this moment all of the procedures followed a pre-determined sequence according to [7]. After the molding, the hollow blocks were kept covered with a plastic film and manually wet, once a day, for 3 days.

\subsection{Physical-Mechanical Tests and Non-Destructive Evaluating Tests (NDE)}

Hollow blocks testing were performed according to the Brazilian Standards for non-bearing blocks according to [7] and [8], respectively, compressive strength and water absorption tests. Besides those tests, the hollow blocks were monitored using the methodology of ultrasonic pulse velocity (UPV) measurement, aiming to obtain indirect information about the kinetics of hydration

Table 3. Blend of normal fraction used in the tests.

\begin{tabular}{|c|c|c|c|c|c|c|c|}
\hline \multirow{3}{*}{$\begin{array}{c}\text { Crop } \\
\text { Residue }\end{array}$} & \multicolumn{7}{|c|}{ MASS CONTENT } \\
\hline & \multirow{2}{*}{ Cement } & \multirow{2}{*}{$\begin{array}{l}\text { Crop } \\
\text { residue }\end{array}$} & \multicolumn{2}{|c|}{ mineral } & \multirow{2}{*}{$\begin{array}{c}\text { Polymer } \\
\text { (SBR) }\end{array}$} & \multirow{2}{*}{$\begin{array}{c}\text { Accelerator } \\
\mathrm{CaCl}_{2}\end{array}$} & \multirow{2}{*}{ wate } \\
\hline & & & sand & $\begin{array}{c}\text { stone } \\
\text { powder }\end{array}$ & & & \\
\hline \multirow{3}{*}{ E. grandis } & 1 & 0.40 & 1.5 & 3 & $5 \%$ & - & \multirow{2}{*}{0.75} \\
\hline & 1 & 0.40 & 1.5 & 3 & - & $3 \%$ & \\
\hline & 1 & 0.40 & 1.5 & 3 & $5 \%$ & - & \multirow{2}{*}{0.55} \\
\hline \multirow{3}{*}{$\begin{array}{c}P . \\
\text { caribaea }\end{array}$} & 1 & 0.40 & 1.5 & 3 & - & $3 \%$ & \\
\hline & 1 & 0.40 & 1.5 & 3 & $5 \%$ & - & \multirow{2}{*}{0.75} \\
\hline & 1 & 0.40 & 1.5 & 3 & - & $3 \%$ & \\
\hline \multirow{2}{*}{ Rice husk } & 1 & 0.36 & 1.5 & 3 & $5 \%$ & - & \multirow{2}{*}{0.50} \\
\hline & 1 & 0.36 & 1.5 & 3 & - & $3 \%$ & \\
\hline
\end{tabular}

Table 4. Composition of the ratios adapted to the cement and residues mixtures.

\begin{tabular}{lcccccccc}
\hline \multicolumn{7}{c}{ MASS RATIO ADOPTED FOR THE MIXTURES } \\
\hline $\begin{array}{c}\text { Composite } \\
\text { type }\end{array}$ & $\begin{array}{c}\text { ce- } \\
\text { ment }\end{array}$ & $\begin{array}{c}\text { crop } \\
\text { residue }\end{array}$ & $\begin{array}{c}\text { Mineral } \\
\text { aggregates }\end{array}$ & $\begin{array}{c}\text { polymer } \\
\text { content } \\
\text { sand }\end{array}$ & $\begin{array}{c}\text { stone } \\
\text { powder }\end{array}$ & $\begin{array}{c}\text { Cement } \\
\text { consumption }\end{array}$ & \\
$\left(\mathrm{kg} \mathrm{m}^{-3}\right)$ & \\
\hline E. grandis & 1 & 0.36 & 1.50 & 3.00 & $0 \%-3 \%$ & 241 & 0.84 \\
P. caribaea & 1 & 0.36 & 1.50 & 3.00 & $0 \%-7 \%$ & 241 & 1.08 \\
Rice husk & 1 & 0.28 & 1.50 & 3.00 & $0 \%-9 \%$ & 268 & 0.65 \\
\hline
\end{tabular}


reaction. Measuring points were selected according to the main directions; groups of points were distributed in three directions (longitudinal, transversal and perpendicular).

The Ultrasonic Tester, model BP7 of Steinkamp, with transducers of exponential section of $45 \mathrm{kHz}$ of resonance frequency were used. This device presents sensibility of $1 \mu \mathrm{s}$ in the measurement of time. For each direction, the average value of UPV was evaluated.

\section{Results and Discussion}

\subsection{Hollow Blocks: Compressive Strength, Water Absorption, Moisture Content and Liquid Area}

Table 5 presents the values for compressive strength according to [7], and Table 6 shows the values of water absorption of the hollow blocks produced in laboratory, according to [8].

Table 5. Compressive strength at 28 days of the hollow blocks residues [7].

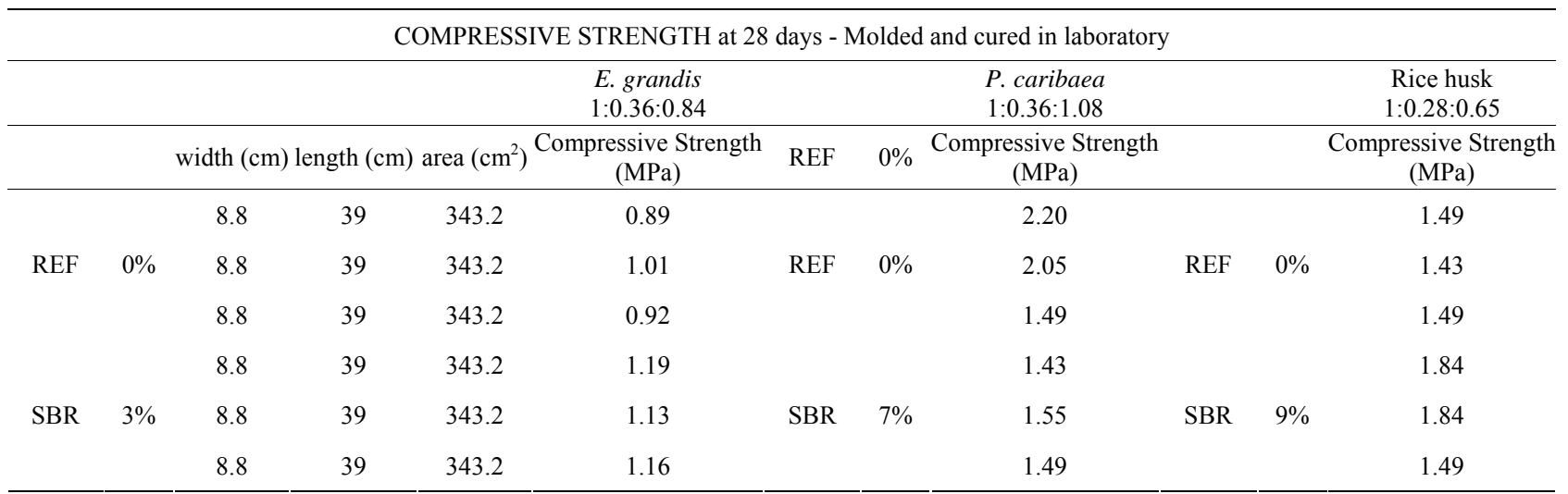

Table 6. Water absorption at 28 days of the hollow blocks residues [8].

\begin{tabular}{|c|c|c|c|c|c|c|c|c|c|c|}
\hline \multicolumn{11}{|c|}{ WATER ABSORPTION, MOISTURE CONTENT AND NET AREA-Molded and cured in laboratory. } \\
\hline & & & $\begin{array}{l}\text { Natural moisture } \\
\text { weight }\end{array}$ & Dry weight & $\begin{array}{c}\text { Saturate } \\
\text { weight }\end{array}$ & Apparent weight & Moisture & Absorption & Net area & $\begin{array}{l}\text { Sample } \\
\text { height }\end{array}$ \\
\hline & & & $\mathrm{m}_{3}(\mathrm{~g})$ & $\mathrm{m}_{1}(\mathrm{~g})$ & $\mathrm{m}_{2}(\mathrm{~g})$ & $\mathrm{m}_{4}(\mathrm{~g})$ & $\mathrm{u}(\%)$ & $\mathrm{a}(\%)$ & Aliq $\left(\mathrm{cm}^{2}\right)$ & $\mathrm{h}(\mathrm{mm})$ \\
\hline \multirow{6}{*}{ 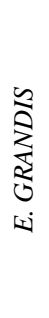 } & \multirow{3}{*}{ REF } & \multirow{3}{*}{$0 \%$} & 5470 & 5310 & 5950 & 3391.5 & 25.00 & 12.05 & 134.66 & 190 \\
\hline & & & 5350 & 5220 & 5810 & 3311.7 & 22.03 & 11.30 & 130.80 & 190 \\
\hline & & & 5430 & 5250 & 5860 & 3340.2 & 29.51 & 11.62 & 133.32 & 191 \\
\hline & \multirow{3}{*}{ SBR } & \multirow{3}{*}{$3 \%$} & 6020 & 5940 & 6720 & 3830.4 & 10.26 & 13.13 & 151.29 & 190 \\
\hline & & & 5780 & 5690 & 6410 & 3653.7 & 12.5 & 12.65 & 145.07 & 190 \\
\hline & & & 5720 & 5640 & 6350 & 3619.5 & 11.27 & 12.59 & 145.24 & 190 \\
\hline \multirow{6}{*}{ 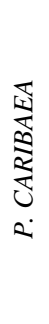 } & \multirow{4}{*}{ REF } & \multirow{4}{*}{$0 \%$} & 6050 & 5960 & 6760 & 3853.2 & 11.25 & 13.42 & 152.19 & 188 \\
\hline & & & 5860 & 5770 & 6580 & 3750.6 & 11.11 & 14.04 & 148.92 & 190 \\
\hline & & & 5980 & 5890 & 6670 & 3801.9 & 11.54 & 13.24 & 150.16 & 190 \\
\hline & & & 6280 & 6170 & 7170 & 4132.5 & 11.00 & 16.21 & 159.03 & 190 \\
\hline & \multirow[t]{2}{*}{ SBR } & \multirow[t]{2}{*}{$7 \%$} & 6230 & 6150 & 7180 & 4149.6 & 7.77 & 16.75 & 158.66 & 190 \\
\hline & & & 6150 & 6040 & 6990 & 3927.3 & 11.58 & 15.73 & 160.35 & 190 \\
\hline \multirow{6}{*}{ 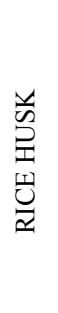 } & \multirow{3}{*}{ REF } & \multirow{3}{*}{$0 \%$} & 6180 & 6060 & 6950 & 3961.5 & 13.48 & 14.69 & 157.29 & 190 \\
\hline & & & 6220 & 6150 & 6980 & 3978.6 & 8.43 & 13.50 & 157.97 & 191 \\
\hline & & & 6340 & 6250 & 7180 & 4164.4 & 9.68 & 14.88 & 158.72 & 189 \\
\hline & \multirow{3}{*}{ SBR } & \multirow{3}{*}{$9 \%$} & 6580 & 6470 & 7340 & 4183.8 & 12.64 & 13.45 & 166.12 & 191 \\
\hline & & & 6610 & 6520 & 7360 & 4195.2 & 10.71 & 12.88 & 166.57 & 190 \\
\hline & & & 6550 & 6440 & 7190 & 4098.3 & 14.67 & 11.65 & 162.72 & 188 \\
\hline
\end{tabular}


The compressive strength and water absorption values for the hollow blocks, molded in laboratory, showed nearest results concerning to the minimum and maximum values suggested by the Brazilian Standard for non-bearing blocks, that is $2.5 \mathrm{MPa}$ and $10 \%$, respectively. Hollow blocks produced in the industry employing the same blend presented smaller compressive strength (1.5 MPa) than the ones molded in laboratory. This fact may be assigned to the hardening process because if it is inadequate, there is a great possibility of early water evaporation, provoking damage on the block's structure, due to the greater porosity of the composite.

\subsection{Ultrasonic Pulse Velocity (UPV)}

In order to measure the ultrasonic pulse velocity (UPV), three possible directions of wave propagation were considered (longitudinal, transversal and perpendicular) as shown in Figure 1.

In the longitudinal direction, the measurements were checked at four positions (Pos 1, Pos 2, Pos 3 and Pos 4), as shown in Figure 2.

In the hollow blocks produced with E. grandis and rice husks there were differences in the UPV values between positions 1 and 2 (upper part of the hollow block) and positions 3 and 4 (lower part of the hollow block), with the higher values corresponding to the lower part of the hollow blocks, for the same age ( 7 days). The higher moisture content at the lower part of the hollow blocks (gravity effect) probably favored the cement hardening in this region. For the hollow blocks from P. caribaea, there was practically no significant difference between

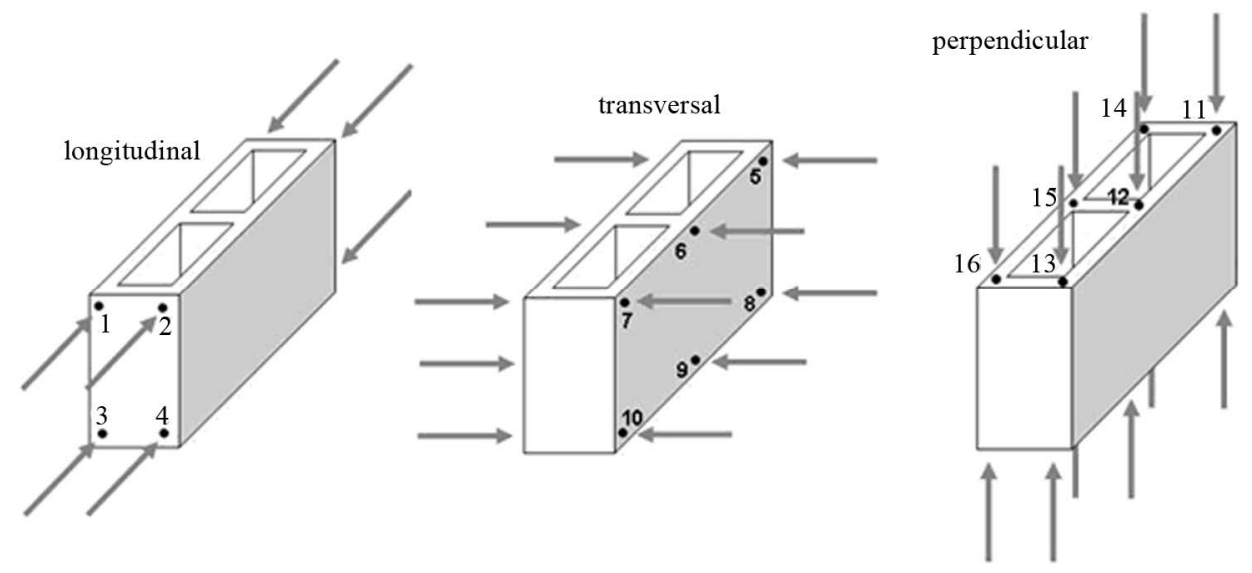

Figure 1. Three possible directions of wave propagations.

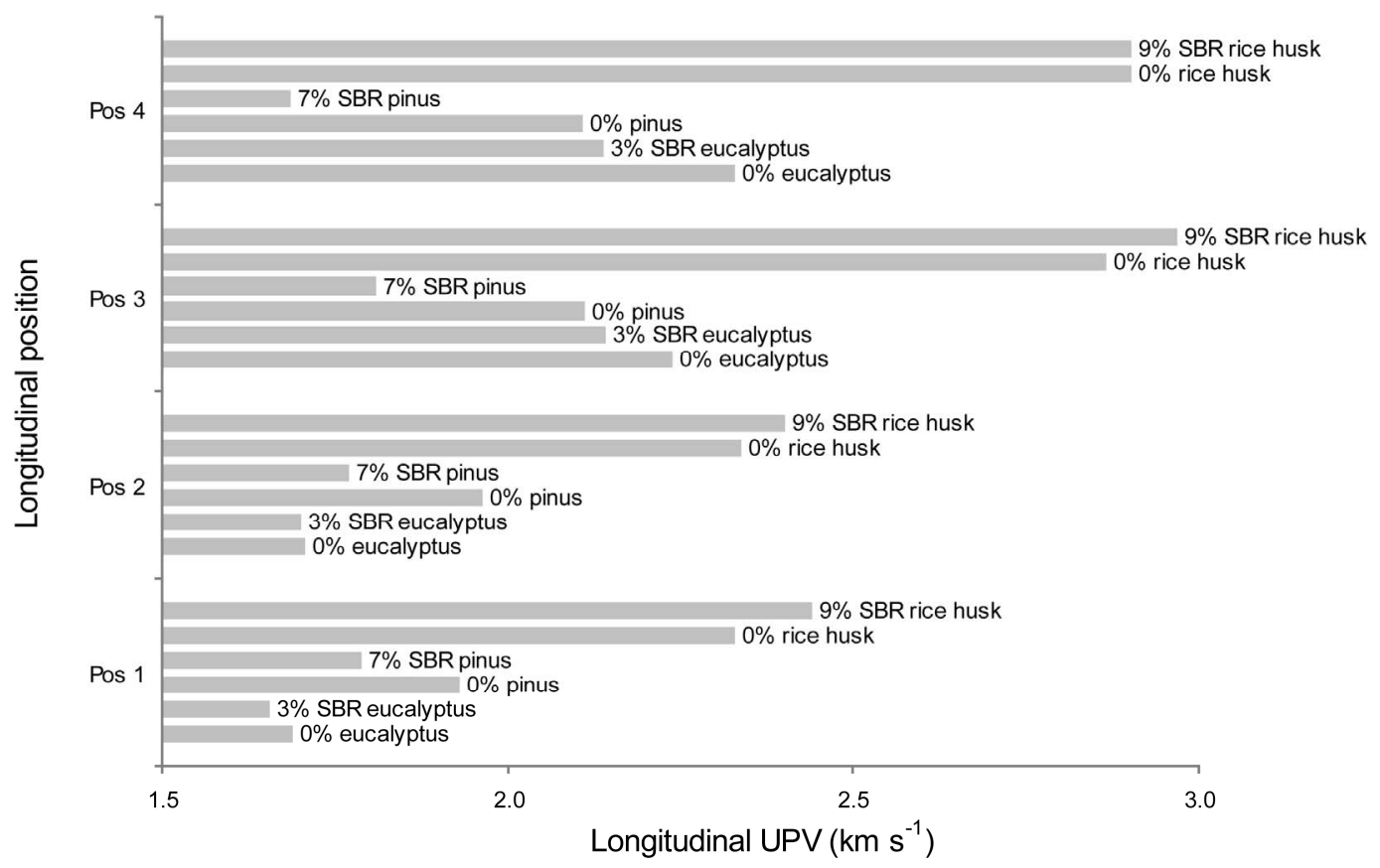

Figure 2. Longitudinal measurements of UPV across the hollow blocks. 
the values obtained at the different points of measuring. The lower values of UPV were obtained in the hollow blocks from E. grandis and from P. caribaea corresponding, in average, to approximately $1.97 \mathrm{~km} \cdot \mathrm{s}^{-1}$ and 1.87 $\mathrm{km} \cdot \mathrm{s}^{-1}$, respectively. The UPV obtained for rice husk hollow blocks presented an average value of approximately $2.64 \mathrm{~km} \cdot \mathrm{s}^{-1}$. The addition of the polymer did not show a significant influence in the magnitude of the UPV value.

In the transversal direction, the measurements were checked at six positions (Pos 5, Pos 6, Pos 7, Pos 8, Pos 9 and Pos 10), as reported in Figure 3.

As similarly related for $P$. caribaea, the hollow blocks produced with $E$. grandis and rice husk presented differences between the values of UPV in positions 5, 6 and 7 (upper part of the hollow block) and positions 8, 9 and 10 (lower part of the hollow block), with the higher values corresponding to the lower part of the hollow blocks, for the same age (7 days). The smallest values of UPV were obtained for hollow blocks of $E$. grandis and $P$. caribaea corresponding, in average, to approximately $2.10 \mathrm{~km} \cdot \mathrm{s}^{-1}$ and $2.04 \mathrm{~km} \cdot \mathrm{s}^{-1}$, respectively. The average value of the UPV for the hollow blocks of rice husk presented an average value of, approximately, $2.80 \mathrm{~km} \cdot \mathrm{s}^{-1}$. The addition of the polymer did not show significant influence on the UPV magnitude.

In the perpendicular direction the measurements were checked at six positions (Pos 11, Pos 12, Pos 13, Pos 14,
Pos 15 and Pos 16), as presented in Figure 4.

The values obtained at the points with positions perpendicular to the hollow blocks did not show significant differences.

A reasonable uniformity was observed in the values obtained for each type of hollow block. The smaller values of UPV were obtained for the hollow blocks from $E$. grandis and from $P$. caribaea corresponding in average to $1.44 \mathrm{~km} \cdot \mathrm{s}^{-1}$ and $1.69 \mathrm{~km} \cdot \mathrm{s}^{-1}$, respectively. The UPV obtained on the hollow blocks from rice husk presented an average value of $1.98 \mathrm{~km} \cdot \mathrm{s}^{-1}$. The addition of the polymer did not show significant influence on UPV.

\section{Conclusions}

The compressive strength and water absorption values of the hollow blocks, molded in laboratory, showed nearest results concerning to the values suggested by the Brazilian Standards for non-bearing hollow blocks. However, the hollow blocks produced in industry do not comply with the values established by the Brazilian Standards. Ultrasound test showed the heterogeneity of the hollow blocks, because there were significant differences in the UPV according to the considered regions. Hollow blocks properties depends on several parameters as the physico-chemical characteristics of the biomass waste, the cement to biomass waste ratio and manufacturing procedures.

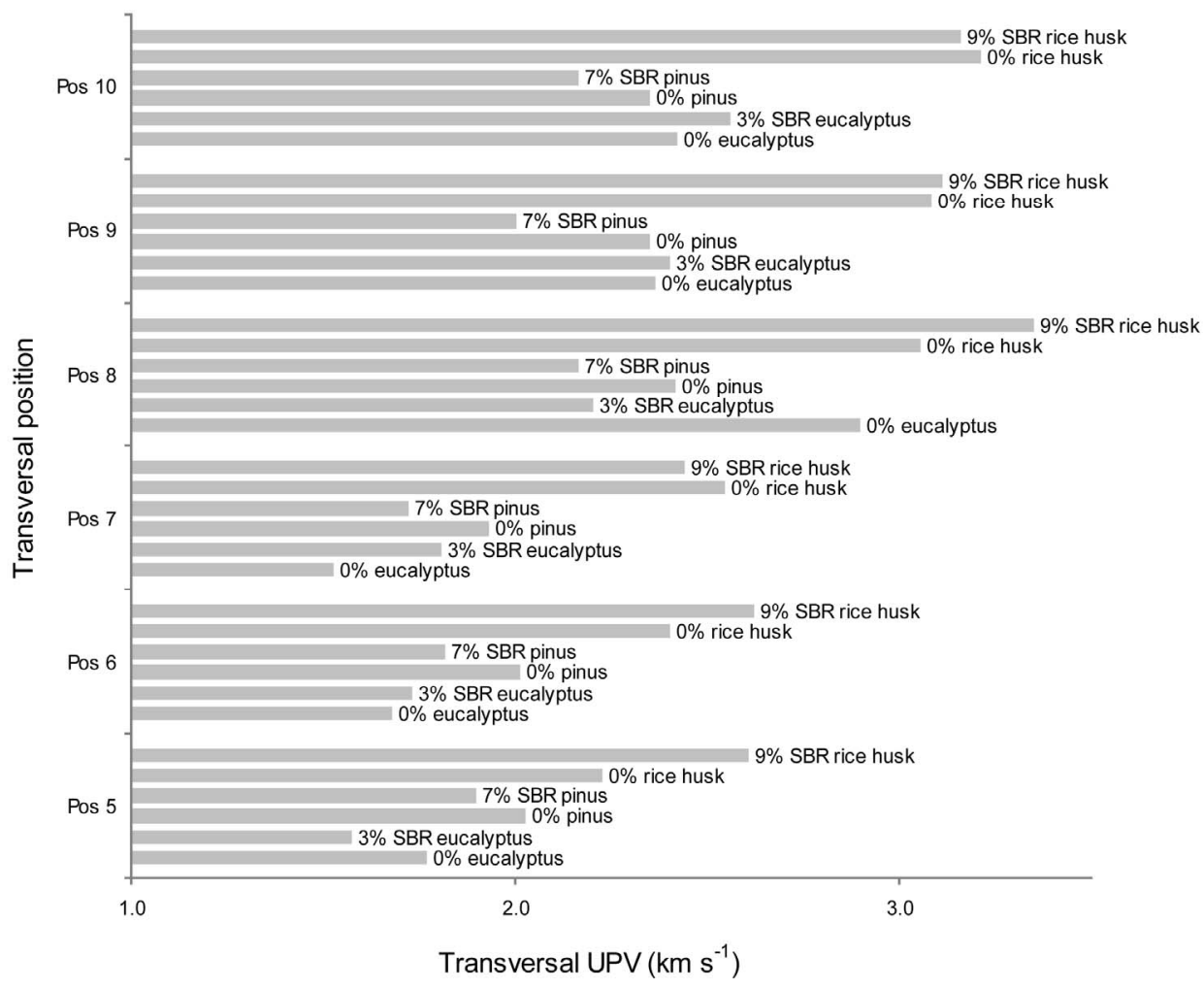

Figure 3. Transversal measurements of UPV across the hollow blocks. 


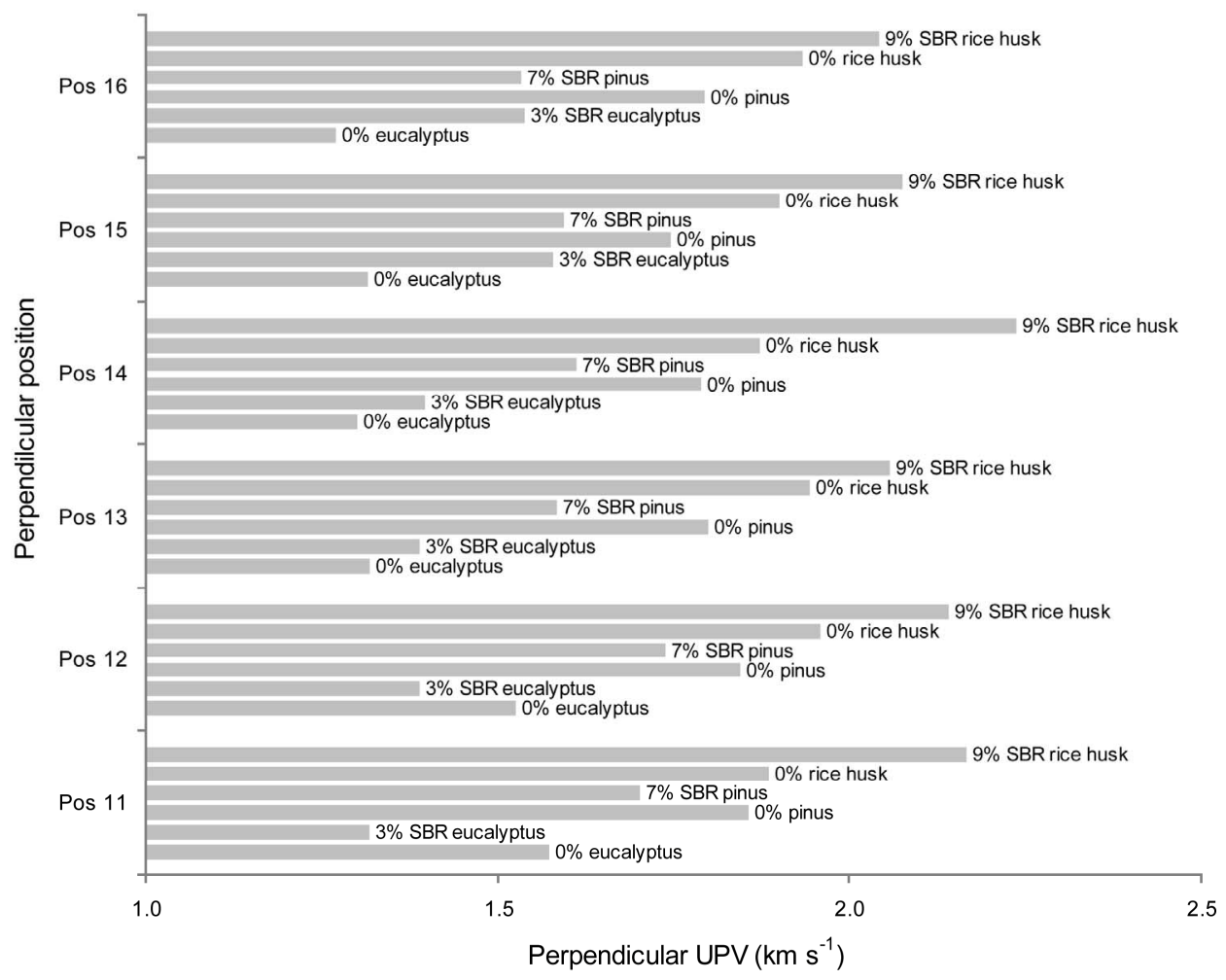

Figure 4. Perpendicular measurements of UPV across the hollow blocks.

\section{Acknowledgements}

The authors thank the technicians of the Laboratory of Materials and Structures of the School of Agricultural Engineering-UNICAMP. They also thank the Laboratory of Materials of the Faculty of Civil Engineering of the State University of Campinas and the Laboratory of Materials of Rhodia Brazil for the polymer supply.

\section{REFERENCES}

[1] A. A. Moslemi, J. F. Garcia and A. D. Hofstrand, "Effect of Various Treatments and Additives on Wood-Portland Cement-Water System," Wood and Fiber Science, Vol. 15, No. 2, 1983, pp. 164-176.

[2] D. P. Miller and A. A. Moslemi, "Wood-Cement Composites: Effect of Model Compounds on Hydration Characteristics and Tensile Strength," Wood and Fiber Science, Vol. 23, No. 4, 1991, pp. 472-482.

[3] Brazilian Association for Technical Standard-ABNT, "High Initial Strength Portland Cement. Specifications," The National Business Review 5733, 1983.
[4] A. C. Stancato, A. K. Burke and A. L. Beraldo, "Mechanism of a Vegetable Waste Composite with PolymerModified Cement (VWCPMC)," Cement and Concrete Composites, Vol. 27, No. 5, 2005, pp. 599-603. doi:10.1016/j.cemconcomp.2004.09.011

[5] L. Beraldo, A. C. Arruda, A. C. Stancato, C. A. P. Sampaio, O. P. Fernandes and V. M. Leonel, "Cement Composites Based on Agricultural Residues," Proceedings of 8th: Wood and Wood Structures Brazilian MeetingEBRAMEM, Uberlândia, 2002, pp. 120-126.

[6] Brazilian Association for Technical Standard-ABNT, "Portland Cement: Determination of the Hydration Heat by the Langavant Bottle Test. Test method," The National Business Review-12006.1990.

[7] Brazilian Association for Technical Standard-ABNT, "Non-Bearing Hollow Blocks: Determination of the Compressive Strength. Test method," The National Business Review-7184, 1991.

[8] Brazilian Association for Technical Standard-ABNT, "Non-Bearing Hollow Blocks: Determination of the Water Absorption, Moisture Content and Liquid Area. Test Method," The National Business Review-12118, 1991. 